\title{
Purchasing good quality eye care: the provider's view
}

\author{
Gilli Vafidis
}

Vision is arguably our most important sense. Loss of vision can isolate a person and fear of blindness is common in people presenting to ophthalmic casualty departments, no matter how trivial their complaint. In 1994 there were 181958 registered blind, and 133823 registered partially sighted in the United Kingdom.

The Royal National Institute for the Blind estimates that underregistration affects two in three eligible adults and that nearer a million people are severely visually impaired in the United Kingdom today. ${ }^{1}$ The social, personal, and financial cost of this is high: there is every reason for our society to invest in healthy eye care.

The main provider of eye care in the United Kingdom is the Hospital Eye Service and it has three principal tasks. Firstly, it provides a diagnostic and treatment facility which restores vision for conditions where sight loss is reversible, for example, cataract.

Secondly, it monitors and treats progressive eye disease to prevent further loss of vision - for example, glaucoma and diabetic retinopathy. Finally, it offers information and help to those whose visual loss is irreversible, for example, in age related macular degeneration.

The hospital eye service is based in hospitals because the equipment and facilities needed for diagnosis, investigation, and treatment are complex and expensive. A basic outpatient kit consists of a slit lamp microscope to give a magnified cross sectional view of the eye, direct and indirect ophthalmoscopes to examine the retina, a tonometer to measure introcular pressure, equipment to test the size and sensitivity of the visual field, and lenses to measure refraction.

More detailed examination requires special photographic techniques some of which use fluorescent dyes, keratometry, ultrasound, and electrodiagnostic tests as well as radiological imaging of globe, orbit, and brain. Specialist nurses, ophthalmic photographers, field technicians, orthoptists, and optometrists are commonly employed in eye departments to supplement and support ophthalmologists.

Treatment in clinic includes topical and systemic drugs, laser surgery, and minor eyelid operations. More complicated procedures require sterile operating theatre facilities with operating microscope, microsurgical instruments, and specialist equipment for small incision surgery and posterior eye disease.
A good eye service strives to provide an effective interface between complex technology and accessible, patient focused care and this is what a purchaser should seek to buy.

In this article I shall outline aspects of the organisation of such a service: in outpatient management, use of clinical guidelines, staff training and development, and education of patient and primary care professionals, performance monitoring, and service developments. I will also indicate what to look for in key ophthalmic conditions, cataract, glaucoma, diabetic retinopathy, macular degeneration, and eye problems in children. Table 1 summarises the list.

\section{The outpatient department}

The outpatient department is where most eye care takes place and good planning is critical to the health of the unit. It is where people have their first, and often only, interaction with the department and yet it may be where there is least evidence of a quality service.

All eye units face the same problem. There are many people to see, an estimated 3.8 million people visit eye departments in England each year, ${ }^{2}$ and as well as volume, other factors combine to foil efficient throughput.

Most patients come from the two extremes of age and have specific transport needs, dependence on escorts, and require special facilities in the clinic. Some are physically or mentally disabled and may be systemically unwell. Inadequate diagnosis in primary care leads to patients needing ancillary tests which cannot be anticipated or prebooked. Some eye problems cannot wait weeks and there must be provision for patients to be seen within 24 hours of referral without their interrupting a booked clinic.

Good outpatient management must incorporate measures which limit the numbers of patients attending, ideally restricting attendance to those who need a specialist opinion. ${ }^{3}$ Measures which include the preview of notes and referral letters by experienced staff encourage adherence to preset care patterns and return visits can be minimised in this way. Outcomes of local guidelines must be monitored against anticipated data so that problems can be identified and guidelines adjusted.

Influencing the quality of new referrals is difficult. General practitioners (GPs) as a whole are 
Table 1 Checklist for ophthalmic purchasing

\begin{tabular}{|c|c|c|c|}
\hline Service & Essential & Preferred & Inappropriate \\
\hline \multirow[t]{3}{*}{ Outpatient service } & $\begin{array}{l}\text { Reduce patient attendances wherever } \\
\text { possible }\end{array}$ & Primary filter for all new referrals & No pretest booking \\
\hline & Local guidelines of patient care & Multiskilling of non-medical staff & $\begin{array}{l}\text { No continuing professional development of } \\
\text { staff in outpatient departments }\end{array}$ \\
\hline & & Specialist clinics & \\
\hline \multirow[t]{3}{*}{ Cataract } & $\begin{array}{l}\text { Patient focused care } \\
\text { Guidelines for listing }\end{array}$ & $\begin{array}{l}\text { Small incision surgery } \\
\text { Regular quality of life and visual outcome } \\
\text { audit }\end{array}$ & $\begin{array}{l}\text { No waiting list validation } \\
\text { No predischarge planning }\end{array}$ \\
\hline & Informed consent & $\begin{array}{l}\text { Delegation to non-medical staff wherever } \\
\text { safe and feasible }\end{array}$ & No short notice list \\
\hline & $\begin{array}{l}\text { Daycare, local anaesthesia operation of } \\
\text { choice }\end{array}$ & & Routine intracapsular surgery \\
\hline \multirow[t]{2}{*}{ Glaucoma } & $\begin{array}{l}\text { Patient oriented approach to individualised } \\
\text { treatment options }\end{array}$ & $\begin{array}{l}\text { More involvement of ophthalmic medical } \\
\text { assistant or glaucoma nurse specialist in } \\
\text { assessment and follow up care }\end{array}$ & $\begin{array}{l}\text { Delegation to community without } \\
\text { adequate guidelines and supervision }\end{array}$ \\
\hline & Flexibility of treatment approach & Eye unit specialist clinic & No specific glaucoma skills training \\
\hline Diabetic eye care & $\begin{array}{l}\text { Adherence to internationally accepted } \\
\text { treatment guidelines }\end{array}$ & $\begin{array}{l}\text { Active participation in multidisciplinary } \\
\text { approach } \\
\text { Specialist clinic }\end{array}$ & $\begin{array}{l}\text { Inadequate training, or guidelines for } \\
\text { assessment and treatment } \\
\text { No access to fluorescein angiography }\end{array}$ \\
\hline $\begin{array}{l}\text { Age related macular } \\
\text { disease }\end{array}$ & Low vision counselling service available & $\begin{array}{l}\text { Clinical teaching to enhance assessment } \\
\text { and treatment }\end{array}$ & $\begin{array}{l}\text { No integration with services for the visually } \\
\text { impaired }\end{array}$ \\
\hline Children's eye diseases & Separate child facilities & $\begin{array}{l}\text { Day care for surgery } \\
\text { Specialist clinic }\end{array}$ & No specialist clinical staff \\
\hline $\begin{array}{l}\text { Links with the } \\
\text { community }\end{array}$ & $\begin{array}{l}\text { Purchaser dialogue on service } \\
\text { developments } \\
\text { Good communication with GPs }\end{array}$ & $\begin{array}{l}\text { Offer training to all community groups } \\
\text { involved with vision }\end{array}$ & No attempt to influence referral patterns \\
\hline Staff training & $\begin{array}{l}\text { Provide continuing medical education and } \\
\text { professional training to all } \\
\text { ophthalmologists and clinical staff }\end{array}$ & $\begin{array}{l}\text { Provide multiskill training in } \\
\text { ophthalmology, interpersonal skills, and } \\
\text { communication }\end{array}$ & No programmes \\
\hline \multirow{2}{*}{$\begin{array}{l}\text { Performance } \\
\text { monitoring }\end{array}$} & Clinical audit programme & Regular appraisal of all eye unit staff & No programme \\
\hline & Regular local guideline revision & $\begin{array}{l}\text { Reports to purchasers on outcomes } \\
\text { Specific issue audits as agreed with } \\
\text { purchasers }\end{array}$ & \\
\hline
\end{tabular}

not confident to manage eye problems and there is a low threshold for referral. ${ }^{4}$

Reducing new referrals into hospital could be achieved by running a preliminary ophthalmic assessment clinic which filters out minor problems, and many good eye units have established such a system in the United Kingdom.

Ideally the filter would be community based and would use one of two ophthalmic professional groups whose members work in the community: the ophthalmic medical practitioner, and the optometrist (the preferred term for ophthalmic optician).

The GP's candidacy for such a role is ruled out by lack of time, ophthalmic training, and equipment, and a wish in general, to refer to a better qualified colleague. The ophthalmic medical practitioner is an ophthalmically qualified doctor who works in the community, mainly testing for glasses. Unfortunately, there are too few ophthalmic medical practitioners to supply every GP practice with a ready ophthalmic opinion. Even if there were sufficient, a lack of career structure and formal professional development programme would make ophthalmic medical practitioner standards difficult to establish and impossible to maintain.

Extension of the role of optometrists to that of gatekeepers for specialist eye care has been proposed as a solution to poor access and long waiting times. ${ }^{5}$ But at the present level of professional training, the optometrist is ill equipped to take on the medical responsibility that this would entail. Furthermore, medicolegal and financial issues would need to be considered before a feasibility study could be piloted. Closer working relations between optometrists and ophthalmologists are being developed in shared care schemes of established ophthalmological disease across the United Kingdom. The Royal College of Ophthalmologists encourages this development provided it is to the benefit of patients. ${ }^{6}$ It may be that such schemes will offer a way of reducing hospital review appointments in the future.

In the absence of a primary care ophthalmologist, some hospital eye service units have established their own filter clinics. Currently there are two models in the United Kingdom. Unfortunately neither has been evaluated.

The most widespread model is that of an ophthalmology preview clinic sited in hospital, either the base hospital or a satellite hospital which does not have in house ophthalmology. Hospital filtering eye clinics are often called primary care clinics and they see only new referrals. Patients attending primary care clinics are given a comprehensive ophthalmological examination. Those with minor 
problems are treated and discharged back to their GP. Patients who require more extensive investigation or further treatment are referred on to the specialist eye unit. Ophthalmologists employed in primary care clinics are not usually consultants and this may lead to inefficiencies unless staff running primary care clinics are undergoing continuing professional development and following effective guidelines of care. It is important for purchasers of a primary care clinic service to satisfy themselves that appropriate decisions are made both with patients referred to the eye unit and those returned to the care of their family doctor.

In the second model, the patient is seen in an eye clinic in the GP's surgery, an outreach clinic. Outreach clinics usually see new and review patients from the host practice and from neighbouring GPs in some cases. They have the advantage of being geographically accessible to the patient who is familiar with local surroundings. Integrated care with the health centre is enhanced, and there is great (largely unrealised) potential for GPs to improve their acquaintance with ophthalmological practice. As in the primary care clinic, the grade, training, and guidance of the staff running the service is all important. A pilot study of ophthalmic outreach clinics ${ }^{7}$ showed that reducing the referral rate into hospital came at high cost if non-consultant staff were used. Second opinions from consultant colleagues in the base hospital accounted for part of the extra expense.

The use of consultant staff in ophthalmic outreach clinics probably improves the efficiency. In our series of 112 consultant outreach clinics only $16.5 \%$ of 1252 new patients were referred for subsequent hospital eye clinic appointments and dates for cataract surgery (12. $5 \%$ of new referrals) were given from the outreach clinics (unpublished data). However, it has been argued that it is inappropriate for consultant ophthalmologists to provide the filter to specialist eye care in the community. ${ }^{2}$

Trying to combine the many roles of an NHS consultant with an outreach service may not be practical until health centres can accommodate full satellite clinics. Until then a reasonable compromise with trained subconsultant staff may be the only outreach option.

Ophthalmological preview clinics have brought two beneficial trends in outpatient management, the team approach and subspeciality clinics (special clinics). The team approach to eye patients has extended the role of nurses, orthoptists, and optometrists who work with doctors in both primary care clinics and special clinics. The delegation and sharing of tasks between medical and non-medical ophthalmic staff is facilitated because responsibilities are more clearly defined. This is beneficial to both patients and staff. ${ }^{8}$ Special clinics also may result in improvements in the quality of care. Staff become skilled at evaluating and managing specific conditions, protocols are easier to establish and evaluate and patient flows become more predictable.

The trend is for even small eye units to have subspecialist clinics-for example, in cataract, glaucoma, diabetic retinopathy, and children's eye diseases-and this, with multiskilling, is an important step towards improving the standard of ophthalmological outpatient care.

\section{Clinical guidelines}

Clinical guidelines provide the link between research and clinical practice. The preparation of national guidelines for ophthalmic care is in its infancy. The Royal College of Ophthalmologists (UK) and The American Academy of Ophthalmology (USA) have issued booklets advising on aspects of care for some conditions. Each document provides guidance on accepted practice with recommendations based on scientific evidence wherever possible, and consensus when no supporting evidence exists. ${ }^{9}$ Although useful for general principles, preferred practice guidelines often do not advise on specific issues and each can be usefully modified to suit local circumstances. ${ }^{10}$ To guide clinicians in process and management of common conditions, each unit should produce local guidelines, developed with the involvement of the staff concerned, and monitored by looking at outcomes that result from their implementation.

\section{Features of individual conditions \\ CATARACT}

A cataract is an opacity in the natural lens of the eye. The commonest cause of cataract is aging of lens proteins, a process hastened by disease, drugs, and trauma. Reduction in vision due to cataract is common, with a prevalence of up to $23 \%$ in those aged $65-74$ years and increasing with age. ${ }^{11}$ There is no proved way of preventing cataract and the condition is treated by removing the opacified lens and replacing it with an inert lens implant. This improves vision and visual function after both first and second eye surgery. ${ }^{12}$

The demand for cataract surgery is likely to rise because there are increasing numbers of elderly people, an increased incidence of cataract, and a lower threshold for surgical intervention. ${ }^{13}$ Purchasers need to find a service which is of high quality and makes efficient use of available resources.

Quality features include; clear criteria for the decision to operate, informed consent including discussion of the type of anaesthesia to be used, the surgical technique, waiting list management, and audit of surgical outcomes.

Efficiency measures include delegation of perioperative care to non-medical ophthalmic staff where possible, use of day care where feasible, and streamlined processes for admission to and discharge from the cataract service.

The unit must have clear guidelines about the requirements for listing for surgery. The presence of cataract alone is not an indication for surgery; there should be discussion and agreement between clinician and patient about predicted and desired visual improvement. Guidelines for visual acuity are useful to indicate a value above which the decision to operate is made only with specific indication, for example, that of a driver dazzled by cataract induced glare. 
Informed consent in elective surgery must embrace the risks and possible complications and yet not exaggerate their incidence. Information about the surgery and perioperative care should be available from eye unit staff, with supplementary pamphlets and tapes.

Local anaesthesia for cataract surgery is well accepted by both patients and staff $\mathrm{f}^{14}$ and avoids the risks of and postoperative recovery from general anaesthetic. For these reasons it should be offered to all patients for whom local anaesthesia is not contraindicated (the profoundly deaf or mentally unstable).

The surgical technique used for cataract extraction has changed over the past 15 years from intracapsular to extracapsular surgery. In intracapsular surgery, the crystalline lens is removed intact, but the operation has an unacceptable complication rate and in routine care is contraindicated. ${ }^{13}$ In extracapsular surgery the membrane naturally enclosing the crystalline lens is left to support a prosthetic lens. Recently, small incision surgery became the extracapsular technique of choice for most ophthalmologists in north America and increasingly in the United Kingdom. ${ }^{15}$ Its advantages are faster wound healing and earlier discharge from postoperative review. However, the technique has yet to be shown to be more cost effective and the result of clinical trials is awaited.

Long delays for cataract surgery must be avoided whenever possible. Theatre space must be used efficiently by minimising cancellations; by giving operation dates in outpatients, assessing patients preoperatively to identify problems ahead of time, validating the waiting list, and using short notice patient lists to fill gaps. Cataract surgery makes up $>75 \%$ of the operative workload of eye units and regular outcome and adverse event audits should be used to monitor the quality of care. Visual acuity is an easily measurable outcome, visual function and patient satisfaction surveys should also be used. ${ }^{16}$

Aspects of perioperative care can be delegated to trained non-medical staff-for example, nurses and ophthalmic medical assistants. Although there are no national guidelines, this seems to be an increasing trend and it will make better use of available skills. Day unit cataract surgery should be used whenever possible. It is cost effective ${ }^{17}$ and safe and is well tolerated by patients. ${ }^{18}$ However, it is essential to involve carers in the discharge arrangements of those who cannot manage alone and where day case uptake is poor for social reasons low dependency beds should be provided for overnight stay.

At the preoperative assessment, predischarge, and follow up arrangements can be planned on the presumption that surgery will go smoothly. But back up arrangements must exist to cope with unanticipated problems. Furthermore, care must be taken to avoid making the process so mechanical that it becomes impersonal and inflexible. Elderly patients need time to discuss individual concerns, preferably with an identified clinical team member who stays with them throughout the episode.
GLAUCOMA

The diagnosis of glaucoma is applied to a group of diseases with a similar clinical pattern of progressive loss of visual field because of damage to optic disc fibres. It is the second most common cause of registerable blindness in the United Kingdom and accounts for one in three ophthalmology outpatient attendances. Open angle glaucoma (the commonest subgroup) affects $5 \%$ of the population by 65 years and it becomes even more common with increasing age. ${ }^{19}$

Risk factors for glaucomatous damage include high intraocular pressure, structural weakness of ocular proteins, and problems with optic nerve blood flow. ${ }^{20}$ Glaucoma may be asymptomatic and advanced disease may be first diagnosed at routine eye examination. There is no cure, field loss is permanent.

The aim of treatment is to prevent further nerve damage by reducing intraocular pressure, but in the presence of multifactorial risk it may only be possible to slow the rate of field loss. It is important, therefore, that glaucoma treatment solves more problems than its unwanted side effects cause.

There are two important aspects to good quality glaucoma care: the patient must be involved in decisions about treatment and eye unit staff must be skilled in assessment and knowledgeable about treatment options.

Compliance with drop therapy depends on patients understanding their disease, reporting side effects, and being aware of treatment risks. Education of patients by informal discussion and counselling, and the availability of pamphlets and tapes about the disease and its treatment are integral to a good service.

Established glaucoma requires lifelong follow up to monitor visual field changes, intraocular pressures and optic disc appearances and thereby to prompt changes in treatment. In an attempt to reduce the need to attend an eye clinic, shared care schemes of stable glaucoma are being piloted with optometrists. However, this is a subspeciality which is seeing rapid advances in computerised imaging of field and disc and consequently glaucoma assessment policies are changing. It may not be the best time to delegate care. The changes should be reflected in upgraded assessment guidelines and glaucoma clinic staff must be trained to apply them.

The treatment choice is between surgery, laser treatment, or medical reduction of intraocular pressure. Each has its risks and benefits, and none can be applied indiscriminately to all patients with glaucoma. ${ }^{21}$ Treatments should be tailored to the individual patient after appropriate discussion. To be able to do this effectively, clinic staff must be kept abreast of current treatment options and be able to select treatments which will prevent significant visual impairment during a person's lifetime without inducing unacceptable side effects.

DIABETIC RETINOPATHY

Diabetic retinopathy occurs as a result of retinal capillary damage by the metabolic consequences 
of diabetes mellitus. It is the leading cause of blindness in the working population of the United Kingdom and it accounts for $7 \%-8 \%$ of all blind registrations. Early treatment with laser photocoagulation of the retina will prevent visual loss in many cases, and it is important that asymptomatic diabetic patients are screened to detect treatable retinopathy before it causes loss of vision. ${ }^{22}$

The hospital eye service is concerned with three aspects of care of diabetic retinopathy; it supports the screening process, it educates patients and clinical staff, and it treats diabetic retinopathy.

There is no national screening programme for diabetic retinopathy; most districts have established a scheme locally which aims to screen all diabetic patients within the area. The eye unit should be involved with this screening programme, offering advice on methods, coordinating training of screeners, and providing assessment and treatment for those referred in by the screening process.

Once retinopathy has been detected, the ophthalmology team should work closely with the diabetic team to educate the patient on the importance of diet, regular exercise and compliance with medication to delay progression of retinopathy. Regular ophthalmological follow up will be needed, even for those with near normal blood sugars because retinopathy will eventually develop here also. ${ }^{23}$ Training for professionals managing diabetic eye disease should be coordinated by the eye unit and should include experience in diabetic clinics, diabetic eye screening, and treatment clinics so that the specialist (nurse and doctor) may be trained in all relevant aspects of the subspeciality. Joint clinics with a physician and an ophthalmologist are useful for continuity of care and training.

Clinics for treatment of diabetic retinopathy should be subspeciality clinics, as special clinic staff become skilled in advising, assessing, and treating patients. The full assessment of retinal vascular disease sometimes requires special photography with intravenous injection of fluorescent dyes (fluorescein angiography) and this technique should be available in every treatment centre. Referral for and interpretation of angiography should also form part of the training curriculum.

Fortunately, the treatment of diabetic retinopathy has been the subject of extensive controlled clinical trials since the 1980 s. $^{245}$ These trials have established the features and classification of diabetic retinopathy which benefit from retinal laser treatment and have resulted in guidelines which are internationally accepted and applied. It is unacceptable for diabetic eye clinic care not to be based on these guidelines.

\section{MACULAR DEGENERATION}

The commonest cause of blind registration in the United Kingdom is age related macular degeneration. ${ }^{26}$ The macula is the area of retina responsible for fine discrimination, and initially there are problems with reading. In up to $20 \%$ of age related macular degeneration a vascular membrane grows under the macula in response to the degenerative change and haemorrhage causes a sudden, often profound, reduction in central vision. Age related macular degeneration can be neither prevented nor treated, although in a few cases laser obliteration of the vascular membrane will be successful in delaying visual loss.

The eye unit has two main concerns in age related macular degeneration. The first is to identify patients who have potentially treatable disease and the second is to provide advice and support where no treatment is possible.

Accuracy of diagnosis and success with laser treatment depends on the education and training of clinicians working in medical retina clinics. Opportunities for discussion of retinal and angiographic findings are important to improve learning opportunities. Because successful treatment is rare, local guidelines are especially important and should be developed and updated in the light of research findings.

In untreatable age related macular degeneration ophthalmologist and patient need to discuss the situation. It is important that the patient is aware that despite loss of central vision, navigational vision will remain. Blind registration where appropriate should be recommended, although the patient often needs time to come to terms with visual loss before low vision aids become useful. ${ }^{27}$

Constructive advice on inexpensive low vision aids should be available in all eye departments. Social services for the visually impaired should be integrated so that the patient will continue to be provided with local support when he or she no longer attends the eye clinic.

\section{CHILDREN'S EYE PROBLEMS}

Unrecognised sight problems in preschool children may result in irreversible visual loss in adulthood. The two common problems that interfere with the development of normal vision are refractive or focusing errors and squint. Either may result in a lazy eye (amblyopia) where, despite normal visual structures the eye does not see.

Amblyopia affects $2 \%-5 \%$ of the population and needs to be detected and treated before the age of seven in most cases. ${ }^{28}$ Recognition and treatment for squint needs to be even earlier for the development of normal stereoscopic vision.

The hospital children's eye service has two aspects, integration with community screening and the management of identified problems.

Usually developmental visual screening is part of the community service. The hospital eye service, however, needs to provide access for referrals and to train non-ophthalmic professionals examining vision in the community.

Clinics are better attended in the community than in hospital (unpublished data) and as non-attendance is a considerable problem in all paediatric clinics, the accessibility of the eye clinic should be a consideration when planning the service. The key person to link community and hospital eye services is the orthoptist, an ophthalmic professional who is specifically 
trained to test for and manage visual problems of young children and who often has sessions in both sites. The hospital eye service should exploit the connection and use it to enhance both services.

Specific training for all involved with children's eye disease is mandatory, and local training by the eye unit should be offered to supplement national programmes. In a hospital environment, the important feature of the service is that it respects the need for staff and facilities to be dedicated to the needs of children. ${ }^{29}$ Senior ophthalmology and anaesthetic staff should have a paediatric special interest. Orthoptists, clinicians, and other ophthalmic staff should examine and treat in paediatric areas of the hospital if space specifically for children cannot be provided within the eye unit. Finally, most eye operations in children should be day cases, ${ }^{30}$ an overnight stay is neither necessary nor convenient for most families.

\section{Staff education, training, and development}

Successful interaction between specialist and patient depends on the specialist using a range of skills. These include interpersonal skills, the communication skills of listening, eliciting and giving information, and professional skills of diagnosis, analysis and decision making, investigation, and treatment. It is part of the role of a good eye unit to enhance the skills of its staff in all these areas, and the training programme should involve all staff in every aspect of care.

Specialist clinics which are diagnosis specific may restrict clinical exposure and the teaching programme must compensate for any deficits in ophthalmological knowledge. Appropriate interclinic referral depends on an understanding of the principles of investigation and treatment of a given condition.

Guidelines should be updated in the light of new research and staff should be encouraged to evaluate published research while developing their own lines of enquiry. Practical ophthalmology, laser surgery and operative intervention must be taught in a way that does not compromise the care or safety of patients or staff.

Education and training will be expected to be provided in part by external courses and meetings which all staff should have the opportunity to attend.

Finally, appraisal should be part of everyone's programme to enhance motivation and give feedback on successes and failures.

\section{Information for patients}

In an increasingly streamlined specialty, well designed patient information has an important place. If patients are to be discharged after one visit, or have rapid transit through a procedure, they must be given relevant information at every stage. It is useful to provide leaflets, which should be easy to read in large clear print with contact telephone numbers for hospital eye service and support groups. Where there are significant numbers of non-english speakers, leaflets should be translated appropriately. Audiotapes are useful for the poorly sighted, and videotapes can be helpful to discuss issues around planned surgery, or to explain treatment options.

\section{Training of other health professionals} involved with eye care

It is important that the hospital eye service develops links with GPs, as ophthalmology is a specialty in which there is too great a reliance on secondary care, with skills and equipment concentrated in the hospital sector. Very few vocational GP trainee schemes involve ophthalmology as part of the rotation, and most GPs consider that their ophthalmological knowledge is substandard. Where the eye unit detects a desire for knowledge in its primary sector, it is important that it exploits it for a well trained GP could reduce significantly the referral rate. ${ }^{31}$

Other professionals in the community are assessing people's eyes-for example, optometrists, school nurses, and health visitors. The eye department should be active in improving the skills of these groups to improve the detection and management of eye disease in the community.

Opportunities must be created for other professionals to develop a special interest in ophthalmology, to link into clinics and training as their skills and time allows.

\section{Monitoring performance}

Useful information can be gained by reviewing the results of processes and interventions. This is an integral part of a successful organisation and should be a routine part of an eye unit's self assessment. The information can be used to improve patient care within the unit and could represent an external index of quality if it were made available to purchasers.

\section{Service developments}

Any developments in the hospital eye service need to take into account likely technological advances, the financial situation, and projected patterns of delivery of care. This means that the planning of new services should be the result of a dialogue between clinicians, local purchasers and agents who have an overview of ophthalmic healthcare provision. An eye unit should seek to establish such a dialogue to develop a strategy for future service developments.

It is a difficult time for providers of secondary health care. Because of increasing pressure from rising emergency admissions, there is less money for predominantly elective specialities like ophthalmology. As a result, maintaining the status quo becomes difficult and investment in new technology nearly impossible. Yet in many ways ophthalmology is a model specialty in the new NHS, it has moved away from dependence on inpatient beds, it can show effective interventions, and it continues to develop satellite clinics for access to primary care. If it can overcome the challenge presented by its outpatient workload, it can move into the 21 st century confident in 
its ability to improve visual health. It is this optimism that keeps morale in good eye units high whatever the financial climate.

1 Bruce I, Mckennell A, Walker E. Blind and partially sighted adults in Britain: the RNIB survey. Vol 1. London: HMSO, adults

2 The Royal College of Ophthalmologists. Hospital eye service. London: Invicta Press, 1996

3 Collins C. Implementing the patient's charter in outpatient services. BMF 1992;304:1396.

4 Featherstone PI, James C, Hall MS, Williams A. General practitioner confidence in diagnosing and managing eve conditions: a survey in south Devon. Br 7 Gen Pract 1992 42:214.

5 Opportunities for the development of primary eye care services. Lambeth: Southwark and Lewisham FHSA, 1996.

6 The Royal College of Ophthalmologists. Shared care. London: Invicta Press, 1996 .

7 Gillam SJ, Ball M, Prasad M, et al. Investigation of benefits and costs of an ophthalmic outreach clinic in general practice. Brf Gen Pract 1995;45:649-52.

8 English T. Personal paper: medicine in the 1990 s needs a team approach. BMF 1997;314:661-3.

9 American Academy of Ophthalmology. Development proces phase ii: development of clinical content. Preferred practice pat tern. San Francisco, CA: American Academy of Ophthalmology, 1996.

10 Small RG, Lloyd Hildebrand P. Guest editorial: preferred practice patterns. Ophthalmology 1996;103:1987-8.

11 Klein B, Klein R, Linton K. Prevalence of age-related len opacities in a population. The beaver dam eye study. Ophopacities in a population. The

12 Javitt J, Brenner M, Curbow B, et al. Outcomes of cataract surgery. Improvement in visual acuity and subjective visual function after surgery in the first, second and both eyes. Arch Ophthalmol 1993;111:686-91.

13 The Royal College of Ophthalmologists. Guidelines for cataract surgery. London: Invicta Press, 1995

14 Hamilton RC, Gimbel A, Strunin A. Regional anaesthesia for 12000 cataract extractions and intraocular len implant procedures. Can 7 Anaesth 1988;615-23.

15 Courtney P. The National cataract surgery survey. 1 Method and descriptive features. Eye 1992;6:487-92

16 Nuffield Institute for Health, University of Leeds. Management of cataract. Effective Health Care 1996;2:3.
17 Aylward G, Larkin D, Cooling R. Audit of cost and clinical outcome of cataract surgery. Health Trends 1993;25:126-9.

18 Lowe K, Gregory D, Jeffery R, et al. Suitability for day case cataract surgery. Eve 1992;6:506-9.

19 Klein BEK, Klein R, Sponsel WE, Franke T, Cantor LB, Martone J, et al. Prevalence of glaucoma: the beaver dam eye study. Ophthalmology 1992;99:1499-504

20 Sommer A. Doyne lecture. Glaucoma: facts and fancies. Evic 1996;10:295-301.

21 Diggory P, Franks W. Medical treatment of glaucoma-a reappraisal of the risks. Br f Ophthal 1996;80:85-9.

22 Rohan TE, Frost CD, Wald NJ. Prevention of blindness by screening for diabetic retinopathy: a quantitative assessment. BMF 1989;299:1198-201.

23 The Diabetes Control and Complications Trial Research Group. The effect of intensive treatment of diabetes on the development and progression of long-term complications in insulin-dependent diabetes mellitus. N Fingl $7 \mathrm{Med}$ 1993;329:977-86.

24 Diabetic Retinopathy Study Research Group. Indications for photocoagulation treatment of diabetic retinopathy DRS Report No 14. Int Ophthalmol Clin 1987;27:239-53

25 Early Treatment Diabetic Retinopathy Study Research Group. Photocoagulation for diabetic macular edema, ETDRS Report No.1. Arch Ophthalmol 1985;103:1796806

26 Evans J, Rooney C, Ashworth F, Dattani N, Wormald R Blindness and partial sight in England and Wales: April 1990 - March 1991. Health Trends 1996;28:5-12.

27 Nilsson UL, Nilsson SFG. Rehabilitation of the visually handicapped with advanced macular degeneration. Do Ophthalmol 1986;62:345-67.

28 Friendly DS. Amblyopia: definition, classification, diagnosis, and management considerations for paediatricians, family physicians and general practitioners. Paediatr Clin North Am 1987;34:1389-401.

29 Audit Commission. Children first: a study of hospital services. London: Her Majesty's Stationary Office, 1993.

30 The Roval College of Ophthalmologists and The British Paediatric Association. Ophthalmic services for children. report of a joint working party. Iondon: RCO and BPA 1994.

31 Sheldrick JH, Wilson AD, Vernon SA, Sheldrick CM. Management of ophthalmic disease in general practice. $\mathrm{Br}$ Gen Pract 1993;43:459-62. 